\title{
OPERADORES CULTURAIS E A PRÁTICA PEDAGÓGICA DA EDUCAÇÃO MATEMÁTICA NOS ANOS INICIAIS
}

\author{
THE CULTURAL OPERATORS IN THE PEDAGOGICAL PRACTICE BY MATH \\ EDUCATION IN THE PRIMARY EDUCATION
}

\author{
Carlos Mometti ${ }^{1}$
}

\begin{abstract}
RESUMO
O presente artigo apresenta um recorte da pesquisa "Educação Matemática nos Anos Iniciais: Aspectos Culturais do Ensinar", iniciada no segundo semestre do ano de 2020 com professores polivalentes da rede pública de ensino de quatro municípios do Estado de São Paulo e um município do Estado do Espírito Santo. Como aporte teórico, considera-se o operador cultural como elemento essencial e constitutivo no que tange à prática pedagógica do professor polivalente, na medida em que se assume a sala de aula como um lugar no qual diferentes culturas são reproduzidas e transformadas. Assim, objetiva-se com trabalho apresentar quais aspectos metodológicos são mobilizados pelo professor polivalente, por meio de operadores culturais, contemplam sua prática de ensino em Matemática. Como fonte de informação foi utilizada parte da entrevista realizada com um dos professores sujeitos da pesquisa. Desta fonte foram extraídos dados, os quais submeteram-se à análise do discurso. Foram identificados os operadores culturais "confiança na prática", "autonomia" e "autoridade na conjuntura". Tais operadores mobilizaram a prática pedagógica do professor entrevistado por meio dos seguintes aspectos: organização dos alunos no processo de ensino, estabelecimento de uma sequência de procedimentos, uso das observações experienciais para reflexão da prática e desenvolvimento de confiança no próprio método.
\end{abstract}

Palavras-chave: Formação docente; Ensino de Matemática; Cultura; Metodologia de Ensino; Polivalentes.

\begin{abstract}
This paper presents an excerpt from the research "Mathematical Education in the Primary Education: Cultural Aspects of Teaching", initiated in the second semester of 2020 with polyvalents teachers from the public school system in four cities in the State of São Paulo and one city in the State of the Holy Spirit. As a theoretical contribution, the cultural operator is considered an essential and constitutive element with regard to the pedagogical practice of the polyvalent teacher, insofar as the classroom is assumed as a place in which different cultures are reproduced and transformed. Thus, the objective of this work is to present which methodological aspects are mobilized by the polyvalent teacher, through cultural operators, contemplate his teaching practice in Mathematics. As a source of information, part of the interview with one of the professors who was the subject of the research was used. From this source, data were extracted, which were
\end{abstract}

${ }^{1}$ Doutorando em Ensino de Ciências, Faculdade de Educação da USP (FEUSP), São Paulo, São Paulo, Brasil / Concordia University, Montreal, Québec, Canadá. Mestre em Educação, Faculdade de Educação da USP (FEUSP). Av. da Universidade, 308, FEUSP, bloco B, LAPEF (lab. 3), Cidade Universitária, São Paulo, São Paulo, Brasil, CEP: 05508-040. E-mail: carlosmometti@usp.br.

ORCID iD: https://orcid.org/0000-0001-6699-7139 
submitted to discourse analysis. The cultural operators "trust in practice", "autonomy" and "authority at the juncture" were identified. Such operators mobilized the pedagogical practice of the interviewed teacher through the following aspects: organization of students in the teaching process, the establishment of a sequence of procedures, use of experiential observations to reflect on the practice and development of confidence in the method itself.

Keywords: Teacher training; Math teaching; Culture; Teaching Methodology; Polyvalents. 


\section{Introdução}

A Educação Matemática vem, nos últimos vinte anos, ganhando espaço no centro das preocupações da pesquisa educacional, não apenas à vista dos resultados aferidos em âmbito nacional - quando assumimos o Brasil como contexto - mas também nos aspectos relacionados à aprendizagem de Matemática em cada nível de ensino.

Nesta perspectiva, tomamos por interesse central, neste trabalho, o estudo da prática docente de Matemática, especificamente no que tange aos anos iniciais. Para isso, consideramos todos os aspectos inerentes ao processo de ensino assumindo-o, sobremaneira, associado de modo intrínseco à aprendizagem. Contudo, como se trata de uma pesquisa, devemos limitar nosso objeto de estudo, destacando o que entendemos por prática pedagógica, escola, professor polivalente e, principalmente, sob qual ótica iremos interpretar os dados transformados.

Não obstante, um dos discursos que mais aparece em decorrência da publicação de resultados por avaliações externas da educação básica - mesmo sendo fundamentado no senso comum e, às vezes, proclamado por entes públicos - é de que o "ensino de Matemática no Brasil não melhora porque os professores da Educação Básica não possuem formação adequada".

Embora este seja um discurso recorrente nas falas cotidianas midiáticas, traz uma bagagem que se materializa culturalmente (BENEDICT, 2013) e que acaba por se incorporar no grupo social, estabelecendo, assim, normatividade. De fato, tal discurso reflete preocupações dos próprios professores polivalentes sobre algo que lhes confere insegurança e, muitas vezes, um sentimento de "mea culpa", por realmente apresentarem dificuldades em Matemática desde sua própria escolarização, optando mais tarde pelo curso de Pedagogia por entenderem ser este um campo antagônico ao das Ciências Exatas (ORTEGA; SANTOS, 2018).

Neste sentido, encontramo-nos num espaço cultural de investigação da prática pedagógica que nos pode evidenciar determinadas dificuldades, no tocante à Matemática Básica, por parte dos professores polivalentes. Além disso, acreditamos que conceitos matemáticos ensinados nesta etapa do ensino são a base para o bom desenvolvimento das etapas posteriores da educação, bem como a obtenção de melhor compreensão matemática por parte dos alunos. 
Assim, investigar quais os conceitos elementares trazem maior dificuldade para os polivalentes de um determinado grupo como, também, quais os procedimentos metodológicos nos anos iniciais são utilizados se justifica na pesquisa em Educação Matemática.

Deste modo, este artigo objetiva apresentar um recorte de pesquisa desenvolvida com professores polivalentes dos anos iniciais do ensino fundamental, tendo como questão central: quais aspectos metodológicos são mobilizados pelo professor polivalente, por meio de operadores culturais, para contemplar sua prática de ensino de Matemática? De forma a obtermos elementos para responder à questão supracitada, o estudo em pauta assumiu, como contexto de análise, um curso de formação continuada em Educação Matemática. Tal curso foi promovido para professores polivalentes da rede pública de ensino de quatro municípios do Estado de São Paulo e um município do Estado do Espírito Santo, durante o segundo semestre do ano de 2020. Neste artigo será apresentado um recorte formado por alguns dos resultados obtidos e analisados sob a perspectiva metodológica da Análise do Discurso.

A pesquisa de que trata o presente recorte, intitulado "Educação Matemática nos Anos Iniciais: Aspectos culturais do Ensinar", foi proposta para ser desenvolvida durante dois anos, dentro da área de Educação Matemática, e tem por objetivo geral investigar as práticas metodológicas utilizadas pelos professores polivalentes dos anos iniciais, buscando identificar e descrever os dispositivos que as operam segundo os pressupostos sociológicos considerados como aportes teóricos. Deste modo, as fontes de informação ainda se encontram na fase de produção dos dados, os quais terão como desdobramentos oferecer à área novas contribuições teórico-metodológicas, bem como propostas metodológicas de formação dos professores que ensinam Matemática nos anos iniciais.

\section{Aportes teóricos}

A metodologia de ensino configura-se como um dos "operadores essenciais" para o funcionamento daquilo que chamamos de escola. Isso significa, de certo modo, que pensarmos a escola é equivalente a pensarmos num múltiplo formado pelos seguintes elementos: espaço, professor, colaborador, aluno e conhecimento, tendo a prática pedagógica como o nodo de ligação entre todos.

Neste sentido, entendemos por "operador" ao conjunto de ações intrinsecamente relacionadas ao termo estrutural em questão. Desta forma, quando dizemos "operador 
cultural" referimo-nos ao conjunto de ações que dizem respeito à cultura do grupo social considerado. Metaforicamente, podemos compreender este conceito comparando-o com o de função matemática, pois esta estabelece uma relação de dependência entre duas ou mais variáveis e, para cada lei de formação, haverá um resultado que depende dos seus valores. O mesmo pode ser entendido por operador dentro do campo sociológico (GIDDENS e SUTTON, 2017).

Assim, os elementos supramencionados estão organizados entre si e formam um mecanismo de autorregulação social, uma vez que a escola, nesta perspectiva, é entendida como uma instituição formada por uma mesoestrutura ${ }^{2}$ da sociedade (GIDDENS, 2013; MOMETTI, 2021).

$\mathrm{Na}$ nossa perspectiva, a escola é vista como uma instituição social de mesoestrutura, como dito anteriormente, a qual também se configura como um espaço físico ou, como a percebemos na pós-modernidade ${ }^{3}$, um espaço digital, gerido por regras estabelecidas de acordo com um documento chamado de Projeto Político Pedagógico (PPP). Neste sentido, cada escola é única e, por isso, respalda seu entendimento como sendo uma mesoestrutura (GIDDENS, 2013; SEWELL Jr, 2005; MOMETTI, 2021). Mediante esta compreensão de escola, podemos diferenciar outro operador essencial, além do metodológico: o operador "cultural".

Este operador se refere à ação dos sujeitos que estão inseridos no grupo, os quais constituem a instituição escolar, uma vez que cada indivíduo é portador de uma cultura e, desta forma, a reproduz no seu meio social ao mesmo tempo em que a transforma (SEWELL Jr, 2005).

Destarte, compreendendo a escola como uma instituição na qual atuam os dois operadores - metodológico e cultural - percebemos que faz sentido interpretá-la partindo de uma perspectiva sociocultural. Além disso, tem-se desta interpretação que a sala de

\footnotetext{
${ }^{2} \mathrm{Na}$ perspectiva adotada por esta pesquisa, entendemos o conceito de mesoestrutura quando comparamos, numa métrica social discutida por Giddens (2013) e estudada por Mometti (2021), as dimensões das estruturas sociais quando assumimos a escola como ponto de análise. A escola, quando estudada de modo localizado, não pode ser vista como macro, uma vez que em um mesmo bairro podemos encontrar diferentes escolas com grupos sociais distintos menores.

${ }^{3}$ A noção de pós-modernidade é aqui inserida de modo a substituir o termo genérico contemporaneidade, segundo a perspectiva de Anthony Giddens, em "As consequências da modernidade" (Editora UNESP). De acordo com este mesmo autor, tal período deu-se a partir dos anos 1970 e caracteriza-se pelas mudanças trazidas, sob a égide estrutural, no campo da economia, trabalho e política ocidentais.
} 
aula é um espaço tanto gerador como reprodutor de diferentes culturas, que se entrelaçam e manejam o conjunto de tradições.

É justamente nesse ponto que podemos desenvolver uma pesquisa educacional direcionando nosso olhar para os operadores essenciais da escola, interpretando a prática pedagógica docente e abrindo possibilidades para sua reflexividade e ressignificação. No que tange à Educação Matemática, podemos citar como um exemplo de operador cultural aquele que mantém nos alunos o "sentimento" de repulsa, ao estudar Matemática. Tal "sentimento", na perspectiva apresentada, foi construído culturalmente por meio daquilo que chamamos de "esquemas de ação" e "recursos" (SEWELL Jr, 2005). Tais esquemas de ação são, basicamente, o conjunto de procedimentos que o professor utiliza para trabalhar os conteúdos da referida disciplina, enquanto os recursos traduzem-se pelos materiais escolhidos para que os esquemas sejam implementados.

Isso significa, pois, que os esquemas de ação utilizados pelo professor são fundamentais para estabelecer padrões culturais pelos alunos quando estudam a Matemática, por exemplo. Por outro lado, não é apenas o aluno ou a aluna que deixa transparecer este sentimento de repulsa com relação à Matemática. Alguns professores também o fazem, pois o operador cultural reproduz padrões que perpassam o grupo social e, com isso, segue de modo geracional, sendo incorporado como prática "natural" daquele grupo específico (BENEDICT, 2013).

Não obstante, cabe à prática pedagógica a manutenção do elo entre os elementos constitutivos de uma instituição escolar. Nesta perspectiva, entendemos por prática pedagógica a mobilização de conhecimentos sistematizados, organizados metodologicamente e com a finalidade de garantir o processo de aprendizagem nos sujeitos envolvidos, ou seja, é um processo que necessita ser intencional, do ponto de vista prático (MOMETTI, 2021).

Assim, tais conhecimentos sistematizados devem, num primeiro momento, passar por uma seleção e atribuição - o que é realizado mediante um currículo, por exemplo para, posteriormente, atuarem de modo sistematizado. Este último processo, por conseguinte, depende única e exclusivamente do professor, na medida em que é aquele que atua diretamente na sala de aula. É exatamente nesse ponto que o operador cultural entra em atividade como dispositivo que influencia o processo de ensino. A figura 1 traz um modelo pictórico da mobilização do operador cultural no elo "prática pedagógica". 
Figura 1 - Representação do operador cultural na prática pedagógica.

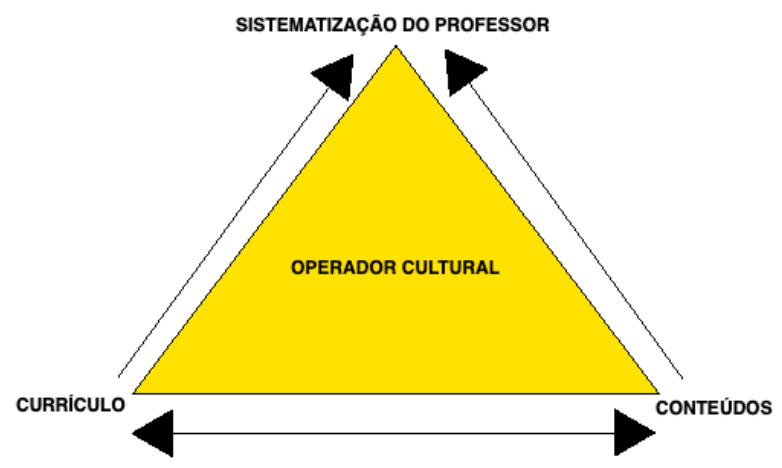

Fonte: o autor.

O elo pode ser interpretado como o perímetro do triângulo, isto é, a prática pedagógica dá-se no perímetro ao passo que o operador cultural cobre a área da figura, permeando todos os padrões e valores que serão reproduzidos e transformados.

Deste modo, o modelo representado na figura 1 nos dá um entendimento de quais vértices podem ser estudados na prática pedagógica para compreendermos potenciais dificuldades do ensino da Matemática, por exemplo.

Cabe ressaltar que a função do modelo acima não é a de desprezar o aluno no processo de ensino e aprendizagem, pelo contrário. Pois, sabemos que é por meio da aprendizagem que a eficácia do ensino se demonstra. Ao aluno, cabe o papel de agente receptor e transformador do processo, pois todos os saberes que lhe são direcionados "percorrem" o espaço entre ele e o professor por meio dos operadores culturais. Por este motivo enfatizamos que nenhum saber é isento de tradição e/ou aspectos ideológicos do professor. O que caberia discutir é de que forma tais elementos tradicionais e ideológicos se manifesta e qual seria sua intensidade no decorrer da prática.

Além disso, outro ponto importante é que, da perspectiva da teoria estruturalista de Giddens (2013), o sujeito constituinte da sociedade exerce uma ação que constrange a estrutura de modo a flexioná-la para possíveis mudanças ${ }^{4}$, do mesmo modo que aquela obriga o indivíduo a se adaptar às suas condições regulativas. Desta forma, no modelo apresentado não há menção excludente à ação promovida pelo aluno dentro da estrutura

\footnotetext{
${ }^{4}$ Segundo Giddens (2013), atua na estrutura social a agência humana ou, como é encontrada na literatura, o agency. Assim, o indivíduo atua de forma a influenciar a estrutura e esta, por sua vez, influencia o indivíduo.
} 
"sala de aula". Adicionalmente, o foco é na prática pedagógica e no estudo do professor, por isso o destaque do modelo para o operador cultural e os vértices que o compõem.

Finalmente, outra ressalva deste modelo é o fato de que a prática pedagógica não é, em hipótese alguma, centralizada na figura do professor, pois há que se considerar os demais agentes do ensino, como os gestores. Por isso o foco do modelo é estudar a referida prática de uma perspectiva sociocultural, em suas múltiplas dimensões.

Deste modo, por meio de informações coletadas do professor, como transcrições obtidas das entrevistas, por exemplo, pode-se investigar como ocorre esta sistematização dos conceitos, quais métodos são utilizados, e a quais aspectos culturais ele recorre para o desenvolvimento da sua prática.

Retomando, neste ponto, a temática da formação do professor pedagogo e seu trabalho com o ensino da Matemática, observamos que sua importância reside no fato de que o caráter polivalente obriga os cursos de formação inicial a estabelecerem currículos de formação geral que lhe garantam uma amplitude significativa das diversas disciplinas, conforme apontam Gatti e Nunes (2009), Julio e Silva (2018), Oliveira e Oliveira (2013), Ortega e Santos (2018) e Mometti (2019).

Não obstante, corroborando com o operador cultural explicitado pelo modelo da figura 1, não é apenas ao conjunto de saberes aprendidos na sua formação inicial ou continuada que os professores polivalentes irão recorrer durante sua prática pedagógica (TARDIF, 2010; MOMETTI, 2020), mas também às vivências obtidas fora da sala de aula. Conforme apontam Julio e Silva (2018), os pedagogos explicitam, por meio de suas narrativas, experiências que trazem aspectos de sua formação enquanto aluno da educação básica, rememorando fatos e formas de ensinar e aprender que estão para além das disciplinas pedagógicas voltadas para o ensino da Matemática.

Desta forma, o modelo do operador cultural mais uma vez pode evidenciar que, para além das poucas disciplinas de Matemática disponíveis nas grades curriculares de Pedagogia (GATTI; NUNES, 2009), o princípio atuante da prática pedagógica do polivalente em Matemática são os padrões culturais obtidos ao longo de sua vida experienciada, e incorporados em sua prática social (BENEDICT, 2013). 


\section{Aportes metodológicos da pesquisa}

O presente trabalho apresenta um recorte da pesquisa "Educação Matemática nos Anos Iniciais: Aspectos culturais do Ensinar" ${ }^{5}$, iniciada no segundo semestre do ano de 2020 e com prazo para realização de dois anos. O objetivo geral da referida pesquisa é o de investigar as práticas metodológicas utilizadas pelos professores polivalentes dos anos iniciais, buscando identificar os dispositivos que operam tais práticas segundo as perspectivas socioculturais apresentadas.

Diante das questões que nortearam o início da pesquisa supramencionada, uma das atividades previstas em seu cronograma de execução era a oferta de um curso de formação continuada para professores polivalentes dos anos iniciais, o qual se deu durante o segundo semestre de 2020. Tal curso foi ofertado pelo período de quatro meses e contou com a participação de cento e cinquenta e cinco professores das redes públicas de ensino de quatro municípios do Estado de São Paulo e um município do Estado do Espírito Santo.

O curso foi ofertado na modalidade a distância por meio de um ambiente virtual de aprendizagem (AVA) e organizado em doze semanas de cinco horas de estudo cada, totalizando uma carga horária total de sessenta horas. Todas as atividades solicitadas para os professores participantes configuram-se como uma fonte de informação para a pesquisa. Uma segunda fonte de informação são as aulas síncronas gravadas, seguindo as normativas dispostas na resolução ${ }^{\circ} 466$ de 12 de dezembro de $2012^{6}$ (BRASIL, 2012). Finalmente, a terceira fonte de informação caracteriza-se por entrevistas realizadas com professores participantes do curso.

Para o recorte proposto no presente artigo, utilizamo-nos de dados transformados a partir de um trecho da entrevista realizada com uma professora participante do curso. Sua seleção deu-se por dois fatores: (i) engajamento durante as aulas síncronas evidenciado pelas questões de natureza conceituais da Matemática e (ii) pela sua atuação nos anos iniciais do ensino público há mais de dez anos.

\footnotetext{
${ }^{5}$ Este projeto de pesquisa conta com o apoio da empresa de objetos educacionais e-learning Mentes Notáveis (São Paulo), do Núcleo de Pesquisa em Inovações Curriculares da USP (NUPIC - FEUSP) e da Coordenação de Aperfeiçoamento de Pessoal de Nível Superior - CAPES - Ministério da Educação do Brasil.

${ }^{6}$ Além da resolução que regula as pesquisas realizadas com seres humanos, foi solicitado para cada participante da investigação um termo de consentimento, no qual se evidenciam os objetivos da pesquisa, o uso e destino dos dados, bem como as informações de contato para solicitação dos mesmos caso tenha interesse.
} 
Para a análise, recorremos à proposta da Análise do Discurso (AD) segundo a perspectiva apresentada Pêcheux (2011). Este autor orienta-nos para uma análise do discurso que considera o fundo ideológico do discurso enunciado. Isso significa que todo discurso transmite uma mensagem ideológica. Além disso, conforme aponta Pêcheux (2011), o discurso pode ser interpretado por meio de entradas disponíveis na superfície discursiva do enunciado dado. Deste modo, tais entradas são a ponta do iceberg para a interpretação do sujeito que analisa. Assim, para toda descrição discursiva caberá uma interpretação a ser construída.

Juntamente com a perspectiva supramencionada, foi acrescentado como dispositivo teórico o conceito de operador cultural evidenciado pelo modelo da figura 1. Neste sentido, a partir do conceito-análise estabelecido por meio da questão de pesquisa, buscamos evidenciar nas superfícies discursivas, obtidas com a entrevista, aspectos culturais que mobilizaram a prática pedagógica da professora polivalente.

No que tange à entrevista, esta fora realizada do tipo semiaberta, seguindo a perspectiva apresentada por Selltiz et al (1987), a qual orienta para a utilização de um roteiro norteador e permite aos entrevistados maior liberdade durante suas respostas, além de possuir como abordagem uma análise mais profunda, corroborando com o disposto por Pêcheux (2011).

Desta forma, o roteiro para a entrevista foi organizado em quatro blocos de questões-norteadoras. Cada bloco era apresentado ao professor e este, por sua vez, ficava livre para comentar, responder de modo direto ou, até mesmo, citar exemplos da sua prática vivenciada. Os blocos da entrevista foram distribuídos nos seguintes temas: (i) Sobre sua vida escolar, (ii) Sobre sua formação pedagógica e universitária, (iii) Sobre sua prática profissional e (iv) Sobre suas perspectivas em Educação Matemática. Neste artigo estão apresentados os discursos analisados referentes ao terceiro bloco da entrevista realizada com ao professor, aqui identificado por "PA". Escolhemos este bloco em particular para análise por cotejar com nosso interesse inicial: estudar quais aspectos metodológicos são mobilizados por operadores culturais e, quais são tais operadores.

No que diz respeito às transformações em dados para análise, ou seja, as transcrições, foi utilizado o método de reprodução por audição "ipsis litteris". Desta forma, foi reproduzido de modo escrito fidedignamente o áudio da entrevista. 


\section{Apresentação dos dados e análise}

A partir das transcrições obtidas do terceiro bloco da entrevista realizada com a professora PA foi realizada a análise do discurso, considerando como conceito-análise a identificação dos operadores culturais que se manifestam para o desenvolvimento da sua prática.

Assim, a partir da leitura flutuante dos discursos transcritos, considerando as marcas discursivas, formação discursiva e formação ideológica, foram identificados por meio da análise três operadores culturais segundo o modelo apresentado pela figura 1. Tais operadores categorizam-se em: "Confiança na Prática”, “Autonomia” e "Autoridade na conjuntura". Os quadros abaixo apresentam os discursos selecionados, com suas respectivas análises.

Quadro 1 - Categorização do operador cultural "Confiança na Prática".

\begin{tabular}{|c|c|c|c|}
\hline Discurso & $\begin{array}{c}\text { Marcas } \\
\text { Discursivas }\end{array}$ & Formação Discursiva & Formação ideológica \\
\hline $\begin{array}{l}\text { Hoje, com os meus alunos, é } \\
\text { como te falei: uso Material } \\
\text { Dourado, eu adoro, eu gosto } \\
\text { dele... Então, quando eles vêm } \\
\text { lá o } 162 \text { ele sabe que aquele lá } \\
\text { é o } 100 \text {, ele sabe que o } 60 \text { não } \\
\text { é o } 6 .\end{array}$ & $\begin{array}{l}\text { Eu adoro, eu gosto } \\
\text { dele. } \\
\text { Ele [aluno] sabe que. }\end{array}$ & $\begin{array}{l}\text { Objetos/recursos que } \\
\text { são úteis para o } \\
\text { ensino. }\end{array}$ & $\begin{array}{l}\text { Ensino com recursos } \\
\text { tradicionais. }\end{array}$ \\
\hline $\begin{array}{l}\text { Então, hoje eu faço os dois } \\
\text { métodos, eu coloco na lousa o } \\
\text { longo e eu coloco na lousa o } \\
\text { simples, e você escolhe, aquele } \\
\text { que você entender melhor (...) } \\
\text { [sobre o ensino da divisão]. }\end{array}$ & $\begin{array}{l}\text { Hoje eu faço. } \\
\text { E você [aluno] } \\
\text { escolhe. }\end{array}$ & $\begin{array}{l}\text { A forma como aplica } \\
\text { na aula para trabalhar } \\
\text { o conteúdo e sua } \\
\text { relação com a } \\
\text { confiança no processo. }\end{array}$ & $\begin{array}{l}\text { O ensino de uma única } \\
\text { forma de resolução não } \\
\text { é eficiente. [Um ensino } \\
\text { não baseado em } \\
\text { manual] }\end{array}$ \\
\hline $\begin{array}{l}\text { Eu sempre chamo de dupla } \\
\text { produtiva, eu gosto muito de } \\
\text { sentar de } 2 \text { em } 2 \text {, até porque na } \\
\text { própria [pausa]... Nas } \\
\text { hipóteses que eles têm de } \\
\text { escrita e de alfabetização, um } \\
\text { ajuda o outro, um puxa o outro } \\
\text { na forma como ele ouve, na } \\
\text { forma como ele pensa, né. } \\
\text { Então, isso ajuda muito. Na } \\
\text { matemática mais ainda! }\end{array}$ & $\begin{array}{l}\text { Eu gosto muito. } \\
\text { Na matemática mais } \\
\text { ainda! }\end{array}$ & $\begin{array}{l}\text { A organização dos } \\
\text { alunos possibilita } \\
\text { desenvolver um } \\
\text { procedimento eficiente } \\
\text { para o trabalho } \\
\text { dificultoso da } \\
\text { matemática. }\end{array}$ & $\begin{array}{l}\text { Aprende-se com o } \\
\text { outro. }\end{array}$ \\
\hline $\begin{array}{l}\text { Isso dá certo, porque } \\
\text { compartilha muito daquilo que } \\
\text { ele acha e, isso eu acho que } \\
\text { aproxima muito, porque às } \\
\text { vezes a criança vem com o } \\
\text { pensamento de que ela não é } \\
\text { capaz (...) }\end{array}$ & $\begin{array}{l}\text { Isso dá certo. } \\
\text { Eu acho que. }\end{array}$ & $\begin{array}{l}\text { O sucesso do } \\
\text { procedimento adotado } \\
\text { é garantido pelo } \\
\text { resultado da } \\
\text { aproximação do } \\
\text { sujeito. }\end{array}$ & $\begin{array}{l}\text { A confiança se constrói } \\
\text { com a aproximação. }\end{array}$ \\
\hline
\end{tabular}


Operadores Culturais e a Prática Pedagógica na Educação Matemática nos Anos Iniciais

\begin{tabular}{|l|l|l|l|}
\hline $\begin{array}{l}\text { Então, ele começa a se } \\
\text { questionar, sabe quem falou, } \\
\text { quem falou que eu não sabia? } \\
\text { Eu sabia fazer exatamente o } \\
\text { que ele fez! Então, ele começa } \\
\begin{array}{l}\text { a se motivar, ele começa a } \\
\text { ficar curioso, ele começa a não } \\
\text { ter medo de perguntar, não tem } \\
\text { medo do colega. }\end{array}\end{array}$ & Ele começa. & $\begin{array}{l}\text { A partir do método } \\
\text { usado o aluno alcança } \\
\text { a autonomia e ganha } \\
\text { independência. }\end{array}$ & $\begin{array}{l}\text { A autonomia é } \\
\text { construída por meio da } \\
\text { eficiência do método. }\end{array}$ \\
& & \\
\end{tabular}

Fonte: o autor.

No quadro 1, representando o operador cultural "Confiança na Prática", o operador é acionado quando a professora relata que "hoje eu faço", ou seja, com sua vivência na prática de ensino daquele conteúdo específico, a professora percebeu que não resultava em uma eficiência para a aprendizagem. Neste sentido, transformou aquele ensino de uma única forma (longa OU simples) no ensino das duas formas (longa $\mathrm{E}$ simples). Com isso, a confiança se materializa, pois a professora acredita que com o ensino das duas formas de resolução das operações de divisão, o aluno terá autonomia para escolher aquele que melhor entende. Isso significa confiança no método.

Por outro lado, ao trazer para seu discurso a expressão "eu gosto muito", o mesmo operador atende ao procedimento utilizado. Pois, amparando-se na experiência e nas dificuldades de ensino da Matemática - evidenciado pelo discurso "Na Matemática mais ainda!" - sugere que aquele modo de proceder no seu método traz resultado e contribui para a aprendizagem. Aqui, a formação discursiva nos diz que a organização dos alunos possibilita o desenvolvimento de um procedimento eficiente para o trabalho dificultoso da Matemática. Além disso, como fundo ideológico identifica-se a ideia de que com o outro se aprende melhor.

Do mesmo modo, ao enunciar a expressão "ele começa", a professora evidencia a eficiência alcançada pelo seu método desenvolvido. Assim, a formação discursiva aparente neste discurso trata de que a partir do método usado o aluno atinge sua autonomia. Claramente, nota-se como fundo ideológico neste discurso a ideia de que a autonomia é construída por meio da eficiência do método escolhido pelo professor, o que coteja com o modelo apresentado pela figura 1. 
Quadro 2 - Categorização do operador cultural "Autonomia".

\begin{tabular}{|c|c|c|c|}
\hline Discurso & $\begin{array}{c}\text { Marcas } \\
\text { Discursivas }\end{array}$ & Formação Discursiva & Formação ideológica \\
\hline $\begin{array}{l}\text { Eu já lecionei no quarto ano, } \\
\text { mas amo os anos iniciais. Amo } \\
\text { a alfabetização, gosto muito. } \\
\text { Estive nos segundos anos, } \\
\text { primeiros anos e, na educação } \\
\text { infantil, que é o antigo pré } 3 \text {, } \\
\text { né, então dava pra alfabetizar, } \\
\text { dá pra fazer bastante coisinha, } \\
\text { na escola particular. }\end{array}$ & $\begin{array}{l}\text { Mas amo os anos } \\
\text { iniciais. } \\
\text { Bastante coisinha. } \\
\text { Na escola particular. }\end{array}$ & $\begin{array}{l}\text { Relação que determina } \\
\text { uma escala de } \\
\text { dificuldade para a } \\
\text { técnica exigida e o } \\
\text { nível de ensino } \\
\text { tratado. }\end{array}$ & $\begin{array}{l}\text { Trabalhar com ensino } \\
\text { infantil e os primeiros } \\
\text { anos é mais fácil. O } \\
\text { ensino público não } \\
\text { possibilita autonomia } \\
\text { no trabalho docente. }\end{array}$ \\
\hline $\begin{array}{l}\text { Todos os dias, quando eu inicio } \\
\text { minha aula, eu faço correção } \\
\text { da atividade, entendeu? Então, } \\
\text { eu já corrijo a atividade e já } \\
\text { levanto a lebre, ali eu já sei o } \\
\text { que ficou para trás, o que não } \\
\text { ficou, o caderninho depois eu } \\
\text { vou olhar e tal (...) }\end{array}$ & $\begin{array}{l}\text { Eu inicio. } \\
\text { Eu faço. } \\
\text { Já corrijo. } \\
\text { Já levanto a lebre. } \\
\text { Já sei. } \\
\text { Eu vou olhar. }\end{array}$ & $\begin{array}{l}\text { A sequência } \\
\text { metodológica que } \\
\text { utiliza para sua prática } \\
\text { e sua relação com a } \\
\text { eficiência de seu } \\
\text { trabalho. }\end{array}$ & $\begin{array}{l}\text { O professor como } \\
\text { centro do processo de } \\
\text { aprendizagem. }\end{array}$ \\
\hline
\end{tabular}

Fonte: o autor.

No quadro 2, ao fazer uso da expressão "amo os anos iniciais", dando destaque para a possibilidade de se "fazer bastante coisinhas" no ensino privado, a professora deixa transparecer, por meio do operador cultural autonomia, que a conjuntura da escola privada possibilita o desenvolvimento de atividades para o referido nível. O ensino público, neste discurso, ficou excluído, o que evidencia que sua estrutura influencia a limitação da autonomia do professor. Além disso, citar a preferência para o ensino infantil e os primeiros anos caracteriza, como processo discursivo, que há uma escolha do lugar de trabalho com relação ao nível associado e com possibilidade do uso de técnicas de ensino mais simplificadas, o que reforça a formação ideológica de que trabalhar no ensino infantil e nos primeiros anos é mais fácil, bem como a ideia cultural de que o ensino público é limitado e difícil.

Da mesma forma, ao discursar, de modo enfático, em primeira pessoa, a professora deixa transparecer a centralização do processo de ensino em seu método. Além disso, aparece em seu discurso uma formação que trata de uma sequência metodológica que utiliza para sua prática e sua relação com a eficiência. Esta última é aludida no seu discurso mediante o uso da expressão "(...) já levanto a lebre, ali eu já sei o que ficou para 
trás". Portanto, deixa claro que o fundo ideológico que sustenta seu discurso é aquele que considera o professor como centro do processo de aprendizagem.

Quadro 3 - Categorização do operador cultural "Autoridade na conjuntura".

\begin{tabular}{|c|c|c|c|}
\hline Discurso & $\begin{array}{c}\text { Marcas } \\
\text { Discursivas }\end{array}$ & Formação Discursiva & Formação ideológica \\
\hline $\begin{array}{l}\text { Eu já falo assim “aqui, nós } \\
\text { podemos dividir? Eu tenho que } \\
\text { olhar o número inteiro, mas eu } \\
\text { tenho que começar por algum } \\
\text { lugar, então eu vou começar } \\
\text { aqui, nas centenas e, aí nós } \\
\text { podemos? Não! Então, vamos } \\
\text { fazer a chave, vamos colocar } \\
\text { esses dois. O } 16 \text { dá para } \\
\text { dividir por 2? Dá!”" }\end{array}$ & Eu já falo assim. & $\begin{array}{l}\text { A forma como aplica } \\
\text { na aula para trabalhar } \\
\text { o conteúdo e sua } \\
\text { relação com a } \\
\text { autoridade. }\end{array}$ & $\begin{array}{l}\text { O professor detém o } \\
\text { conhecimento } \\
\text { verdadeiro. }\end{array}$ \\
\hline $\begin{array}{l}\text { Na primeira reunião, falo para } \\
\text { os pais “se você aprendeu a } \\
\text { sua, teve a sua experiência, } \\
\text { guarda para você, deixa o seu } \\
\text { filho ter a dele, a lição que vai } \\
\text { para casa, quando ele volta } \\
\text { para mim diz assim professora } \\
\text { eu não consegui, eu preciso } \\
\text { saber, porque eu tenho que } \\
\text { fazer alguma coisa melhor } \\
\text { para ele entender. Porque, } \\
\text { senão ele vai passar a vida } \\
\text { inteira sem entender. E ele não } \\
\text { vai entender o seu jeito, porque } \\
\text { você entendeu de uma forma } \\
\text { que é sua e, ele precisa } \\
\text { encontrar a forma que é dele } \\
\text { de entender”. }\end{array}$ & $\begin{array}{l}\text { [Eu] Falo. } \\
\text { Guarda para você. } \\
\text { Eu preciso saber. } \\
\text { Eu tenho que fazer. } \\
\text { Uma forma que é } \\
\text { sua. }\end{array}$ & $\begin{array}{l}\text { Relação de autoridade } \\
\text { do método ensinado } \\
\text { pelo professor sobre o } \\
\text { conhecimento comum } \\
\text { e experiencial dos pais } \\
\text { para com os filhos. }\end{array}$ & $\begin{array}{l}\text { O conhecimento do } \\
\text { professor é verdadeiro } \\
\text { e não deve ser } \\
\text { substituído. }\end{array}$ \\
\hline
\end{tabular}

\section{Fonte: o autor.}

Finalmente, no quadro 3, ao evidenciar por meio das marcas discursivas em primeira pessoa, tais como "[eu] falo", "eu preciso" e "eu quero", a professora deixa clara a centralização da aprendizagem das crianças em seu método de ensino. Isso significa que o operador cultural autoridade, como anteriormente, entra em ação em sua prática pedagógica por meio daquilo que considera como o mais eficiente e construído pela sua experiência, cotejando com o modelo apresentado na figura 1. Neste sentido, atribui como fundo ideológico para seu discurso aquele operador que pressupõe o conhecimento do professor como único e verdadeiro, e que não deve ser substituído. 


\section{Conclusões}

Mediante o apresentado neste artigo, consideramos que os operadores culturais influenciaram a prática pedagógica da professora entrevistada. Partindo do modelo de análise sugerido pela figura 1 deste artigo, evidencia-se a importância de se trabalhar, por meio de uma análise de dados, a busca de dispositivos culturais que se manifestam na prática docente.

Com os dados apresentados nos quadros de 1 a 3, foi possível perceber as marcas discursivas que operaram no discurso, culminando no fundo ideológico destacado e, por conseguinte, evidenciando os operadores culturais buscados. Assim, de modo a responder à questão inicial que norteou este trabalho, podemos dizer que os aspectos metodológicos que foram mobilizados por meio dos operadores culturais categorizados como "Confiança na Prática", “Autonomia" e "Autoridade na conjuntura" concentraram-se nos seguintes: organização dos alunos no processo de ensino, estabelecimento de uma sequência de procedimentos, uso das observações experienciais para reflexão da prática e desenvolvimento de confiança no próprio método.

Portanto, estudarmos os aspectos culturais por meio do discurso do professor darnos-á pistas para repensarmos sua prática pedagógica na Educação Matemática e, deste modo, direcionarmos melhores ações no que tange aos cursos de formação inicial e continuada, tanto para pedagogos como para licenciados.

Por outro lado, um dos fatores limitantes do trabalho encontra-se na análise do discurso realizada sobre os enunciados discursivos. Pois, segundo Pêcheux (2011) todo discurso cabe uma interpretação. Esta, por sua vez, deve estar o máximo possível isenta de configurações ideológicas por parte do pesquisador. Neste sentido, buscamos analisar todos as marcas discursivas de modo puramente teórico e a identificar as formações discursivas, ideológicas e quais os operadores culturais que se manifestaram. Para tanto, conforme prevê, ainda, a vertente francesa da $\mathrm{AD}$, o processo de análise inicia-se com a leitura flutuante, mas esta não pode ser o único momento de contato do pesquisador com os enunciados tratados.

Finalmente, como se trata de um recorte de pesquisa, este artigo traz à luz da pesquisa em Educação Matemática um modelo para estudo da metodologia de ensino dos professores polivalentes no que tange à Matemática dos anos iniciais. Deste modo, darnos-á elementos teórico-metodológicos que poderão ser aprofundados e desenvolvidos e, 
possivelmente verificados, para outros níveis de atuação do professor, tais como os anos finais do ensino fundamental e o ensino médio.

\section{Referências}

BENEDICT, R. Padrões de Cultura. Trad. Ricardo Rosenbusch. São Paulo: Vozes, 2013.

BRASIL. Ministério da Saúde. Conselho Nacional de Saúde. nº 466 de 12 de dezembro de 2012. Disponível em < https://bvsms.saude.gov.br/bvs/saudelegis/cns/2013/res0466_12_12_2012.html $>$. Acesso em 20 jan. 2021.

GATTI, Bernadete; NUNES, Marina Muniz Rossa. Formação de professores para o ensino fundamental: estudo de currículos das licenciaturas em pedagogia. São Paulo: Fundação Carlos Chagas - Pesquisas Educacionais, 2009.

GIDDENS, Anthony e SUTTON, Philip W.; Conceitos essenciais de sociologia. Tradução de Claudia Freire, 1. Ed. São Paulo: Editora Unesp Digital, 2017.

GIDDENS, Anthony. A constituição da sociedade. Tradução Álvaro Cabral. São Paulo: Martins Fontes, 2013. 458p.

JULIO, Rejane Siqueira; SILVA, Guilherme Henrique Gomes da Silva. Compreendendo a Formação Matemática de Futuros Pedagogos por meio de Narrativas. Bolema, v.32, n.62, p.1012-1029, 2018.

MOMETTI, Carlos. Construindo experiências em um curso de formação de professores dos anos iniciais: o ensino da Matemática em foco. Anais do I Congresso

Internacional Educat, Universidade Federal de Pernambuco, Recife, Brasil, p. 282 291, 2019.

MOMETTI, Carlos. Estudo da Prática Docente no Ensino de Física. Mauritius: Novas Edições Acadêmicas, 2021. 121p.

MOMETTI, Carlos. Novos tempos exigem novas posturas: o papel do professor na Educação 4.0. Anais do Congresso Internacional de Educação e Tecnologias (CIET), Universidade Federal de São Carlos, São Carlos, Brasil, 2020.

OLIVEIRA, Gaya Marinho; OLIVEIRA, Ana Terese de C. C. A matemática na formação inicial de professores dos anos iniciais: reflexões a partir de uma análise de teses e dissertações defendidas entre 2005 e 2010 no Brasil. Em teia: Revista de Educação Matemática e Tecnológica Iberoamericana, v.4, n.1, 2013.

ORTEGA, E. M. V; SANTOS, V. M. A relação dos alunos do curso de pedagogia com o conhecimento matemático e seu ensino: um estudo longitudinal. Revista Holos, V.2, ano 32, p.207-2024, 2018. Disponível em < 
http://www2.ifrn.edu.br/ojs/index.php/HOLOS/issue/view/140>. Acesso em $12 \mathrm{dez}$. 2020.

PÊCHEUX, Michel. Análise do Discurso. 1 ed. Ed. Pontes, 2011. 316p.

SELLIZ, Claire; WHRIGHTSMAN, Lawrence; COOK, Stuart Wellford. Métodos de pesquisas nas relações sociais. São Paulo: EPU, 1987.

SEWELL JR., W. H. Logics of history: social theory and social transformation. Chicago: Chicago University Press, 2005.

TARDIF, M. Saberes docentes e formação profissional. Tradução Francisco Pereira. São Paulo: Editora Vozes, 2012. 